\title{
SOBRE A FECUNDIDADE DAS CRISES
}

\section{(D) Wilma Peres Costa ${ }^{1,2}$}

A célebre formulação feita por Hegel, em 1818, sobre a filosofia como o pássaro de Minerva, que ergue seu voo quando a noite começa a cair, fala-nos de sombras, mas também de uma luz crepuscular. O claro-escuro é uma técnica potente para ressaltar contornos. A luz que emana do crepúsculo e que envolve aqui os objetos e o pássaro que sobre eles adeja é vista na sua dimensão paradoxal: potente para reconhecer os contornos do mundo, mas associada irremediavelmente às formas maduras e prestes a fenecer, pode reconhecer essas formas, pode compreendê-las, mas não pode rejuvenescê-las. A mesma percepção ele estende à história, destinada, como a filosofia, a refletir sobre coisas findas e formas maduras, no momento em estas desvelam a sua finitude, sem poder projetar sua luz sobre o futuro.

Penso nessa formulação hoje, em meio a uma tragédia social e humana de proporções ainda não totalmente compreendidas - a pandemia do Covid19 - e sua capacidade de arrasar vidas, corroer instituições e formas de sociabilidade privadas e públicas e vejo nela um desafio e um convite à insubordinação. Parece impossível que não consigamos, pelo recurso à memória coletiva e às narrativas que herdamos de tantas outras pestes do passado, aprender alguma coisa com essa tristeza. A trágica revelação de que a doença e o desemprego tornam ainda mais desiguais os desiguais e a percepção de que a dimensão pública da vida (inclusive a saúde e a escola públicas) é condição da própria sobrevivência dos indivíduos e do seu direito a ter esperança já se apresentaram à humanidade outras vezes e em algumas delas algo aprendemos.

1 Universidade Federal de São Paulo. Guarulhos - São Paulo - Brasil.

2 Wilma Peres Costa (Departamento de História, Unifesp) é historiadora e socióloga. Autora, entre outros trabalhos de Cidadãos e Contribuintes - estudos de história fiscal, SP: Alameda, 2020. 
Como historiadora, sei muito bem que a disciplina está muito distante de ser um repertório de exemplos, ou a "mestra da vida" como se pensou no passado. Se aprendemos com a história, de modo que ela nos ajude a projetar o futuro, não é pelo exemplo dos acontecimentos passados, mas pela certeza de que, na constante transformação que é nossa condição, algo permanece - as adversidades nos ensinam por que elas nos defrontam com conjunturas em que, por mais que tentemos, não conseguimos reproduzir as formas de vida que consagramos, às quais nos habituamos e com as quais pretendíamos planejar o dia de amanhã, como nos ensinou um mestre e amigo inesquecível. E desse confronto, doloroso embora, emergem novos projetos e novas práticas.

Foi assim naquele distante ano de 1918, quando no final da Grande Guerra (que ainda não era chamada de Primeira, porque não se imaginava que aquela insânia pudesse de novo acontecer) vieram à luz três importantes estudos que procuravam entender as razões da tragédia. A luz crepuscular, naquele momento, projetava-se sobre as cinzas da Europa e desvelava os fundamentos do típico artefato do "longo século XIX": o estado-nação, que pareciam diante de um desafio insuperável.

Dois desses estudos nasceram no campo dos derrotados, um dos quais, a Áustria, perdia a condição de cabeça de um grande e multifacetado Império. Refiro-me ao ensaio de Max Weber, Parlamentarismo e Governo numa Alemanha Reconstruída e ao pequeno e aparentemente despretensioso artigo de Joseph Schumpeter, The crisis of the tax state, apresentado originalmente como conferência na Viennese Sociological Society ${ }^{3}$. O terceiro ensaio originava-se no campo dos que se acreditavam vencedores - a Inglaterra - muito embora o esgarça-

3 Escrito a partir de uma conferência proferida em 1918, o ensaio foi republicado, entre outros lugares, em SWEDBERG, Richard (org.). Joseph A. Schumpeter, The Economics and Sociology of Capitalism. Princeton: Princeton University Press, 1991, pp. 99-141. O ensaio de Max Weber teve tradução brasileira como "Parlamentarismo e Governo numa Alemanha Reconstruída: uma contribuição à crítica política do funcionalismo e da política partidária”. WEBER, Max. Vol. 37 da Col. Os Pensadores. Tradução Maurício Tragtenberg. São Paulo: Ed. Abril, 1980. p. 01-85 (1ª Ed. 1918). 
mento dos liames de seu poderoso Império já claramente se prenunciasse, o que se confirmaria nas décadas subsequentes. Dos três, é também o mais sombrio: As consequências econômicas da paz, de John Maynard Keynes ${ }^{4}$, vaticinando os dramáticos efeitos que poderiam advir das exigências draconianas que os aliados pretendiam impor à Alemanha.

Embora muito diferentes em seus temas e proposições, esses trabalhos possuem em comum alguns traços que vale a pena aqui enfatizar. Em primeiro lugar, eles buscaram ajustar o foco de sua luz crepuscular para perscrutar algumas das estruturas do estado-nação, no modo como elas se davam a conhecer pela sua própria crise, projetando-a, ainda que melancolicamente, para o futuro. A forma que ela ilumina é a da democracia parlamentar contemporânea e seus mecanismos, dentre os quais o orçamento público - esse horizonte de expectativa de que dependia da legitimidade do estado e da representação política para estabelecer onde se deveria gastar os recursos penosamente arrecadados dos cidadãos/eleitores/contribuintes. Como convencer a todos eles a continuar pagando seus impostos, entregando seus filhos ao recrutamento militar obrigatório, quando as montanhas de recursos obtidos pelo consentimento dos cidadãos-contribuintes se haviam dilapidado na feérica fogueira da destruição de vidas, propriedades, indústrias, plantações, estradas e portos, provocada pela guerra total? Haveria um futuro para o estado fiscal, perguntava Schumpeter? Poderiam as forças organizadas da sociedade, expressas nos seus sistemas parlamentares, voltar a estabelecer legitimidade na arrecadação de impostos que poderiam terminar nesse espetáculo macabro de destruição coletiva? Max Weber compartilhava, de certo modo, essas preocupações, assestando sua crítica sobre a burocratização e o déficit representativo do estado alemão, onde o sistema bismarckiano teria forjado uma sociedade invertebrada e pouco dotada de resiliência e criatividade. O que em Schumpeter reverberava como

4 KEYNES, John Maynard, As Consequências Econômicas da Paz, Brasília: Ed. Univ. Brasília, IPRI, 2002. 
dúvida e apreensão aparecia em Weber como caminho desejado para a Alemanha de 1918, com a valorização das possibilidades da política e da vida parlamentar. Seria esse caminho capaz de se contrapor ao que aparecia a ele como um avatar do burocratismo - o comunismo soviético, que encontrava múltiplos simpatizantes na sociedade alemã?

Enquanto o peso e o alcance da representação parlamentar na vida política aparece como questão candente para os pensadores alemães, para Keynes é a própria "psicologia da sociedade" que se encontra em causa, pela absurda destruição do esforço humano pela máquina de guerra, gestada no interior dessa própria ordem liberal, e com ela, o nexo moral que alicerçava o 'espírito do capitalismo': como justificar as hierarquias sociais de um mundo que se fizera caduco, como reativar os valores que davam sentido ao mundo do século que se encerrava - trabalho, poupança, frugalidade? Como conjurar, enfim, que as classes populares se vissem irremediavelmente atraídas pelas promessas do socialismo?

A pergunta nos conduz para o segundo ponto que enlaça os três trabalhos aqui enfocados. Na extremidade da Europa, e também movido pela tragédia da guerra, surgia um novo modelo de organização econômica e política. A Revolução Soviética mostrava que o socialismo deixara de ser um espectro e adquiria uma materialidade que atraía as esperanças de vastos setores, como as greves que pipocaram em todo o mundo, no ano de 1917 bem demonstravam.

Entre as interrogações vividas pela democracia liberal, a urgência de estabelecer os fundamentos de uma reconstrução possível e o temido prestígio da experiência soviética, esses ensaios iriam compartilhar um terceiro ponto de aproximação - não receberam boa acolhida quando vieram a público, nem conferiram prestígio aos seus autores, mas ganhariam, sim, enorme repercussão nos anos subsequentes à segunda guerra mundial.

As reflexões de Keynes, que conclamavam os aliados à tolerância com a Alemanha derrotada, foram conjuradas pelos seus compatriotas, tornando-o suspeito até mesmo de traição. Mas elas viriam, mais tarde, em diálogo nem sempre fácil com as correntes socialistas, for- 
matar ferramenta teórica vigorosa da construção do estado de bem-estar social e do fortalecimento dos estados democráticos europeus na reconstrução do pós-guerra. Ao mesmo tempo, a monumental obra weberiana se tornaria referência incontornável da sociologia, da ciência política e da reflexão histórica do século XX, tematizando as principais vertentes da historicidade do estado e das formas representativas nas democracias liberais. Menos fortuna teria o texto de Schumpeter, esquecido por longo tempo nos anais de um congresso. Os economistas sempre preferiram, no conjunto de sua obra, o elogio do "empresário inovador" às sábias considerações sobre as estruturas do estado e a natureza das democracias. O que faltava ao texto de Schumpeter naquele momento talvez fosse a capacidade de prever o futuro, o que é fatal para as pretensões da ciência econômica. O estado fiscal, que ele via em crise talvez irremediável, iria não só se recuperar como ampliar sua capacidade arrecadadora, provendo estruturas de atenção social para as demandas sociais do pós-guerra, em abrangência nunca imaginada pelos historiadores do século XIX. O pequeno ensaio desprezado pelos economistas, tornou-se, entretanto, seminal para várias gerações de historiadores. Isso talvez porque Schumpeter tenha buscado a história para enfrentar o impasse que ele percebia para a crise do estado fiscal, e deslocando o seu lugar de estudo para os liames conflituosos que antepõem as pulsões extrativas do estado e as resistências de súditos e cidadãos. A fiscalidade deixava os cânones estreitos dos montantes de arrecadação, para abrir um rico campo de possibilidades de estudo e, por que não, uma agenda política amadurecida para as forças democráticas.

Essas reflexões, em diferentes linhagens, têm ceifado o campo que passou a ser reconhecido como o da sociologia histórica e a das teorias da construção do estado, onde laboraram pioneiramente Barrington Moore Jr., Perry Anderson, Charles Tilly, entre muitos outros, em fronteiras compartilhadas entre a história, a sociologia e a economia 
política ${ }^{5}$. Pensar o estado-nação historicamente, em suas estruturas, fiscais, jurídicas, militares e simbólicas tem sido a grande contribuição dessas indagações.

Se lemos ainda hoje com proveito essas reflexões é porque, para os historiadores as crises podem ser epistemologicamente fecundas, pois ao impor desafios e impasses, elas nos obrigam a desnaturalizar nossos objetos. É desse modo que podemos produzir resultados capazes de iluminar e compreender nossas práticas e, por que não, indicar saídas.

Essas reflexões me ocorrem porque não posso deixar de pensar que vivemos novamente uma crise e que precisamos aprender com ela. É evidente também que a nossa crise tem uma dimensão fiscal inequívoca. Mas que ela não está radicada nas dificuldades em reduzir nosso endividamento ou ambicionar um quimérico equilíbrio fiscal. Ela implica novas perguntas, e temos que formulá-las como o fizeram nossos autores aqui lembrados, como impasses que não podem ser resolvidos com velhas fórmulas. Temos um desafio civilizatório e temos que enfrenta-lo aumentando e não reduzindo os gastos públicos para minorar a nossa enorme dívida social. Parece evidente que a sociedade mais igualitária e mais sustentável que desejamos não surgirá agora, como não surgiu em 1918, do jogo do mercado. Naquele momento, o jogo do mercado fez apenas o aprofundamento da crise e pavimentou o caminho de uma nova guerra. Não é o que queremos, não é uma escolha que podemos ter. Nossa meta fiscal não pode ser o ajuste por que não há um passado para o qual voltar. Nosso desafio

5 Ver também MOORE JR. Barrington, Origens Sociais da Ditadura e da Democracia, São Paulo: Martins Fontes, 1983 e SKOCPOL, Theda. Estados e revoluções sociais: análise comparativa da França, Rússia e China, São Paulo: Ed. Presença, 1985. Ver também Perry ANDERSON, Linhagens do Estado Absolutista, SP: Ed. Brasiliense, 1985. Para uma abordagem referencial, oferecida pela sociologia histórica ver: TILLY, Charles, (ed). The Formation of National States in Western Europe. Princeton: Princeton University Press, 1975, e, também, TILLY, Charles, Coerção, capital e cidades europeias. (trad.port.) São Paulo: Edusp, 2001. Ver também John A. HALL (ed.). Os Estados na História, Rio de Janeiro: Imago, 1992. Ver também BONNEY, Richard (ed.). The rise of the fiscal state in Europe c.1200-1815 e BONNEY, Richard (ed.). Economic Systems and State Finance, Oxford: Oxford University Press, 1999. 
não é restaurar o passado, mas o futuro. O futuro humano depende do combate à desigualdade, da relação sustentável com a natureza, da tolerância com os diferentes, vale dizer, do aprofundamento da democracia. As bases da reconstrução só podem ser essas, ou não haverá futuro.

Crepuscular, embora o voo da ave de Minerva seja capaz de construir a travessia, até que ouçamos os galos tecendo a manhã.

\section{Referências Bibliográficas}

ANDERSON, Perry. Linhagens do Estado Absolutista, SP: Ed. Brasiliense, 1985.

BONNEY, Richard. Economic Systems and State Finance, Oxford: Oxford University Press, 1999.

BONNEY, Richard. The rise of the fiscal state in Europe c.1200-1815. Oxford: Oxford University Press, 1999.

COSTA, Wilma Peres. Cidadaos e Contribuintes - estudos de historia fiscal, SP: Alameda, 2020.

HALL, John (ed.). Os Estados na Historia, RJ: Imago, 1992.

KEYNES, John Maynard, As Consequências Econômicas da Paz, Brasilia: Ed. Univ. Brasilia, IPRI, 2002.

MOORE JR. Barrington, Origens Sociais da Ditadura e da Democracia, SP: Martins Fontes, 1983.

SKOCPOL, Theda. Estados e revolucoes sociais: analise comparativa da Franca, Russia e China, SP: Ed. Presenca, 1985.

SWEDBERG, Richard (org.). Joseph A. Schumpeter, The Economics and Sociology of Capitalism. Princeton: Princeton University Press, 1991.

TILLY, Charles (ed). The Formation of National States in Western Europe. Princeton: Princeton University Press, 1975.

TILLY, Charles. Coercao, capital e cidades europeias. (trad.port.) Sao Paulo: Edusp, 2001. 
WEBER, Max. "Parlamentarismo e Governo numa Alemanha Reconstruida: uma contribuicao a critica politica do funcionalismo e da politica partidaria”. Vol. 37 da Col. Os Pensadores. Traducao Mauricio Tragtenberg. Sao Paulo: Ed. Abril, 1980. p. 01-85 (1ª Ed. 1918).

Recebido em: 08/07/2020 - Aprovado em: 04/08/2020 